\title{
A FORMA DE ORGANIZAÇÃO COMPOSICIONAL DO GÊNERO RESENHA ACADÊMICA: UMA ANÁLISE DAS SEQUÊNCIAS DISCURSIVAS E DE SUAS FUNÇÕES
}

\author{
LA FORMA DE ORGANIZACIÓN COMPOSICIONAL DEL GÉNERO RESEÑA ACADÉMICA: UN ANÁLISIS DE \\ LAS SECUENCIAS DISCURSIVAS Y DE SUS FUNCIONES
}
THE FORM OF COMPOSITIONAL ORGANIZATION OF REVIEW AS ACADEMIC GENRE: AN ANALYSIS OF DISCURSIVE SEQUENCES AND THEIR FUNCTIONS

Gustavo Ximenes Cunha ${ }^{1}$

Universidade Federal de Alfenas - UNIFAL-MG, Alfenas, BR

\begin{abstract}
RESUMO: Este trabalho investiga o impacto das propriedades do gênero resenha acadêmica sobre sua estrutura composicional e explicita o papel que as sequências discursivas exercem nessa estrutura. Com base nos postulados do Modelo de Análise Modular do Discurso, analisamos quatro exemplares do gênero resenha. As análises permitiram constatar que, nesse gênero, as sequências descritivas são empregadas para apresentar o livro resenhado e caracterizar o tópico de cada capítulo. Já as sequências argumentativas são usadas para avaliar partes do livro e para recomendar ou não o livro.

PALAVRAS-CHAVE: resenha; sequências discursivas; modularidade.
\end{abstract}

RESUMEN: Este trabajo investiga el impacto de las propiedades del género reseña académica sobre su estructura composicional y explicita el papel que las secuencias discursivas cumplen en esa estructura. Con base en los postulados del Modelo de Análisis Modular del Discurso, analizamos cuatro ejemplares del género reseña. Los análisis permitieron constatar que, en ese género, las secuencias descriptivas son empleadas para presentar el libro reseñado y caracterizar el tópico de cada capítulo. Ya las secuencias argumentativas son usadas para evaluar partes del libro y para recomendar o no el libro.

PALABRAS CLAVE: reseña; secuencias discursivas; modularidad.

ABSTRACT: This paper investigates the impact of properties of academic review on its compositional structure and explains the role of the discursive sequences in this structure. On the basis of the postulates of the Modular Approach to Discourse Analysis, we analyze four occurrences of the genre review. The analyses showed that, in this genre, the descriptive sequences are employed to present the book and the topic of each chapter. The argumentative sequences are used to evaluate parts of the book and to recommend or not the book.

KEYWORDS: review; discursive sequences; modularity.

\section{INTRODUÇÃO}

A resenha acadêmica é um gênero cuja finalidade principal é a de permitir a um especialista convencer o leitor a adquirir ou não uma obra recentemente publicada, funcionando como um guia de aquisição de publicações (CARVALHO, 2005). Nesse sentido, a resenha é um gênero fortemente persuasivo, já que por meio dela esse especialista avalia a contribuição que a obra traz para uma dada área dos conhecimentos, as características da composição e a capacidade do autor.

Essas propriedades situacionais do gênero poderiam levar à hipótese de que os seus exemplares, no nível de sua estrutura composicional, são formados exclusiva ou predominantemente por sequências discursivas de tipo argumentativo, não havendo espaço para sequências pertencentes a outros tipos, como a narração e a descrição. Uma hipótese como essa se fundamenta nos vários estudos da Linguística do Texto e da Análise do Discurso que apontam correlações entre as propriedades situacionais ou contextuais de gêneros do discurso e as propriedades linguísticas e textuais dos exemplares desses gêneros.

\footnotetext{
1 Doutor em Linguística pela UFMG. Professor-Adjunto do Instituto de Ciências Sociais Aplicadas (ICSA) e do Programa de Pós-Graduação em Gestão Pública e Sociedade (PPGPS), ambos da UNIFAL-MG. E-mail: <ximenescunha@yahoo.com.br>.
} 
É assim que, estudando o gênero debate, Burger (2002) observa que a necessidade de tornar esse gênero mais atraente para o público leva o jornalista/mediador do debate a assumir uma postura menos neutra e, consequentemente, a utilizar uma quantidade maior de recursos textual-discursivos destinados a transformar o debate em debate-espetáculo². No estudo das transações comerciais em livraria, Filliettaz (2000, 2008) aponta para o papel que expectativas ligadas a esse gênero exercem no desenvolvimento das ações de livreiro e cliente em situações específicas. Nessas situações, percebe-se o papel configurante dessas expectativas para a realização de ações locais. Ao analisar o gênero diário de leitura, Machado (1998) observa que nesse gênero as descrições, contrariando o protótipo descritivo de Adam (1992), apresentam elementos avaliativos, o que, segundo a autora, justifica acrescentar uma fase de avaliação ao protótipo descritivo que subjaz às sequências descritivas desse gênero.

Nessa mesma perspectiva, este trabalho tem como finalidade verificar a pertinência da hipótese segundo a qual os exemplares do gênero resenha seriam formados exclusiva ou predominantemente por sequências argumentativas, investigando o impacto das propriedades situacionais do gênero sobre sua estrutura composicional e explicitando o papel que as sequências discursivas exercem nessa estrutura.

Com base nos postulados teóricos e metodológicos do Modelo de Análise Modular do Discurso (ROULET; FILLIETTAZ; GROBET, 2001), analisamos quatro exemplares do gênero resenha acadêmica, publicados em periódicos da área de Ciências Sociais Aplicadas. Antes de apresentar, de modo detalhado, cada uma das etapas em que a análise se desenvolveu, procederemos a uma breve exposição do Modelo de Análise Modular do Discurso.

\section{UM MODELO PARA O ESTUDO DA COMPLEXIDADE DISCURSIVA}

O Modelo de Análise Modular do Discurso constitui um instrumento de descrição e explicação da complexidade discursiva. Em sua versão atual (FILLIETTAZ; ROULET, 2002; MARINHO; PIRES; VILLELA, 2007; ROULET; FILLIETTAZ; GROBET, 2001), o modelo compõe um quadro teórico e metodológico que visa reunir, em uma mesma abordagem da complexidade da organização do discurso, as contribuições de pesquisadores que se centraram em aspectos isolados dessa organização.

O esforço pela criação de um modelo, ao mesmo tempo, amplo e preciso justifica-se pela constatação de que

a construção e a interpretação do discurso são submetidas a três tipos de restrições: restrições que podemos chamar situacionais, ligadas ao universo de referência e à situação de interação; restrições linguísticas, ligadas à sintaxe e ao léxico da (ou das) variedade(s) de língua(s) utilizada(s), e restrições textuais, ligadas à estrutura hierárquica do texto. (ROULET; FILLIETTAZ; GROBET, 2001, p. 44).

Por isso, o modelo modular constitui um instrumento de análise, que permite integrar e articular, em uma perspectiva cognitivo-interacionista, as dimensões linguística, textual e situacional da organização do discurso.

Reconhecendo que o discurso é um objeto cuja organização e cujo funcionamento envolvem aspectos dessas diferentes dimensões, Roulet (ROULET; FILLIETTAZ; GROBET, 2001) encontra na modularidade um método satisfatório para dar conta da organização do discurso. Ao aplicar esse método ao estudo do discurso, o modelo modular considera ser possível descrever, por exemplo, o sistema da língua independentemente da situação de interação em que ela é utilizada, bem como descrever as estruturas sintáticas de uma produção discursiva sem fazer referência à estrutura conceitual que subjaz a ela. Descritas de modo independente as informações que participam da organização do discurso, o modelo postula ainda que essas informações podem ser combinadas, a fim de se descreverem os diferentes aspectos envolvidos na produção e na interpretação dessa organização complexa que é o discurso.

Conforme essa metodologia, identificam-se inicialmente os módulos que entram na composição do discurso. Um módulo é definido como um sistema de informações elementares, o qual deve fornecer a descrição de um domínio específico da organização discursiva. Nessa abordagem, considera-se que cada dimensão do discurso se constitui de módulos. Assim, a dimensão linguística se constitui dos módulos lexical e sintático; a

2 Desses recursos, fazem parte marcadores de oposição, como negações e conectores contra-argumentativos, marcadores de subjetividade, como pronomes pessoais de $1^{\text {a }}$ pessoa, marcadores de topicalização, estruturas clivadas, etc. 
dimensão textual se constitui do módulo hierárquico; e a dimensão situacional se constitui dos módulos interacional e referencial.

Definidos os módulos, é possível descrever e explicar, em seguida, como as informações modulares se combinam em formas de organização do discurso. Na produção e na interpretação de toda forma discursiva, as informações de origem modular se interrelacionam em unidades complexas de análise, que são as formas de organização. No modelo modular, distinguem-se dois tipos de formas de organização: as elementares e as complexas. As formas de organização elementares (fono-prosódica, semântica, relacional, informacional, enunciativa, sequencial, operacional) resultam da combinação ou acoplagem de informações extraídas dos módulos. Já as formas de organização complexas (periódica, tópica, polifônnica, composicional, estratégica) resultam da combinação ou acoplagem de informações extraídas dos módulos e das formas de organização elementares e/ou complexas.

Neste estudo, analisamos quatro exemplares do gênero resenha acadêmica, os quais foram publicados em periódicos da área de Ciência Sociais Aplicadas ${ }^{3}$ O objetivo foi o de compreender o impacto das propriedades situacionais do gênero resenha sobre sua estrutura composicional, explicitando o papel que as sequências discursivas exercem nessa estrutura.

Para alcançar esse objetivo, a análise se desenvolveu em três etapas. Na primeira, as resenhas foram estudadas do ponto de vista do módulo referencial, a fim de investigar as ações que os resenhistas tipicamente realizam ao produzirem um exemplar desse gênero. Na segunda etapa, as resenhas foram analisadas do ponto de vista da forma de organização sequencial, com o fim de identificar as sequências (narrativas, descritivas, argumentativas) que entram na composição desses textos. Em seguida, na terceira etapa da análise, as informações obtidas nas etapas anteriores foram combinadas no interior da forma de organização composicional, para se chegar a uma compreensão aprofundada do papel das sequências discursivas na realização das ações de produção da resenha acadêmica. A continuação deste trabalho apresenta os resultados dessas três etapas da análise.

\section{ANÁLISE DO MÓDULO REFERENCIAL}

O módulo referencial é definido no modelo modular como o responsável pela descrição das relações que o discurso mantém com o mundo no qual é produzido, bem como das relações que ele mantém com o(s) mundo(s) que representa. Conforme Roulet (1996, p. 22, grifo do autor), "esses mundos podem analisados em representações mentais de tipo praxeológico, para as ações, e de tipo conceitual, para os seres e as coisas". Assim, esse módulo busca dar conta, de um lado, das ações linguageiras e não-linguageiras realizadas ou designadas pelos parceiros de uma interação e, de outro lado, dos conceitos ativados em tais ações.

O tratamento em um mesmo módulo de entidades aparentemente distintas como as ações e os conceitos se justifica pela relação de interdependência que as caracteriza. De fato, uma mesma representação mental pode ser descrita sob o ponto de vista praxeológico ou sob o ponto de vista conceitual. Numa situação específica, as propriedades conceituais e os percursos acionais ligados a uma representação mental se acham relacionados. Isso porque, assim como não se concebe a ação sem os conceitos nela implicados, também não se concebem os conceitos fora da ação que os mobiliza (ROULET; FILLIETTAZ; GROBET, 2001, CUNHA, 2008).

No estudo do módulo referencial, considera-se que as ações e os conceitos são parcialmente regulados por expectativas tipificantes. De acordo com Filliettaz (ROULET; FILLIETTAZ; GROBET, 2001, p. 105), "os acontecimentos passados deixam traços na experiência do presente". A existência desses traços ou marcas de acontecimentos passados indica que "as relações dos indivíduos com seu ambiente não são radicalmente 'inventadas' por eles, mas necessariamente 'mediadas' por indexações sociais e conhecimentos coletivos interiorizados".

\footnotetext{
${ }^{3}$ Das quatro resenhas, uma foi publicada, em 2011 , no volume 31 (1) da Revista de Economia Política. Outra foi publicada, em 2004, no volume 4 (7) do periódico Economia e Gestão. As outras duas resenhas foram publicadas, respectivamente, em 2009 e 2010 , nos volumes 49 (4) e 50 (3) da Revista de Administração de Empresas.
} 
As expectativas tipificantes, decorrentes da existência desses traços, não exercem um determinismo forte sobre o desenvolvimento das interações. Ao contrário, elas explicitam expectativas provenientes de experiências passadas, compartilhadas intersubjetivamente, cuja função é orientar os indivíduos. Nas interações efetivamente realizadas, os interactantes mobilizam as expectativas tipificadas, atualizando-as em configurações particulares. Essas configurações particulares podem ser definidas como o produto emergente da negociação instaurada entre os interactantes ao longo de um dado discurso.

Dessa maneira, o módulo referencial se ocupa tanto da descrição de representações esquemáticas (praxeológicas e conceituais), referentes às expectativas tipificantes subjacentes ao discurso, quanto da descrição de estruturas emergentes (praxeológicas e conceituais), referentes às configurações particulares e resultantes de realidades discursivas específicas (FILLIETTAZ, 1996, ROULET; FILLIETTAZ; GROBET, 2001).

Tendo em vista os objetivos deste trabalho, tratamos apenas do componente praxeológico (acional) das produções discursivas. Ao abordar o componente praxeológico, um dos objetivos do módulo referencial é o de explicitar alguns recursos tipificantes ligados à realização e à identificação de ações no mundo. No modelo, o instrumento de análise desenvolvido para alcançar esse objetivo é a representação praxeológica.

A representação praxeológica busca descrever alguns percursos acionais típicos de uma interação. Com essa representação, não se pretende descrever o conjunto de todas as ações que podem efetivamente ser realizadas pelos interactantes, mas, sim, apreender elementos de experiências anteriores, sobre as quais se fundam as condutas presentes (FILLIETTAZ, 1997). Dessa forma, "ela não determina as ações, mas opera como um guia cognitivo subjacente" (MARINHO, 2002, p. 243).

Como a representação praxeológica resulta de elementos de experiências anteriores, ela não é estritamente individual, devendo ser considerada, portanto, como um construto coletivo, "ao qual devemos atribuir uma validade social" (ROULET; FILLIETTAZ; GROBET, 2001, p. 128). Assim, à transação de compra e venda de um livro, por exemplo, subjaz uma representação praxeológica que comporta preferencialmente as ações de entrar, cumprimentar, comprar/vender um livro, pagar, agradecer, sair (ROULET, 1995, ROULET; FILLIETTAZ; GROBET, 2001).

A análise dos quatro exemplares do gênero resenha acadêmica revelou um percurso acional típico, ou seja, uma recorrência nas ações realizadas pelos resenhistas e na ordem de realização dessas mesmas ações. Em todas as resenhas, foi possível identificar uma sequência de ações típicas. Assim, os resultados dessa etapa da análise mostraram que, ao resenhar um livro, um resenhista desenvolve basicamente quatro ações: 1) apresentação do livro; 2) caracterização do livro; 3) avaliação de partes do livro; 4) recomendação ou não do livro .

No começo da resenha, o resenhista costuma dar uma visão geral do livro, como ocorre neste trecho

(01) A sociologia econômica é um campo em desenvolvimento. (...) Inserida nesse campo de estudos, Redes e sociologia econômica é obra organizada pela professora Ana Cristina Braga Martes.

Em seguida, o resenhista caracteriza, de modo bem geral, o tópico de cada capítulo ou das partes do livro.

(02) A obra está estruturada em três grandes partes que se desdobram, evidenciando a sucessão de teorias, críticas e proposições em gestão estratégica de pessoas. A primeira aborda a gestão estratégica de pessoas como alinhamento sistêmico. A segunda, como potencial competitivo. A terceira, em seus temas contemporâneos.

Na sequência, o resenhista apresenta de modo mais detido o conteúdo de cada capítulo, avaliando e discutindo pontos específicos. Nessa avaliação, podem ser apontados os méritos do livro:

(03) Outra característica marcante da obra é a postura crítica assumida ao longo de todo o texto. A leitura não se restringe à passividade, mas desperta, a todo momento, a reflexão em função dos pontos e contrapontos apresentados continuamente pelo autor.

Ou essa avaliação pode ser o apontamento do que o resenhista considera um problema: 
(04) A obra poderia conter, também, um capítulo de conclusão, conferindo mais espaço a esclarecimentos, discussões e interrelações entre capítulos. Indo além, dada a natureza complexa do tema, seria interessante que os capítulos teóricos da primeira parte viessem todos acompanhados de textos associados, com comentários de autores convidados,

Por fim, o resenhista recomenda ou não o livro.

(05) Neste sentido, para todos aqueles que desejam pensar o Brasil num cenário de desenvolvimento e não apenas pela ótica das políticas econômicas de curto prazo, recomenda-se a leitura dos ensaios elaborados em honra do Professor Werner Baer, que mesclam, com competência técnica, as dimensões múltiplas do processo de desenvolvimento da America Latina.

Nessa parte final, a recomendação pode ser acompanhada de alguma crítica.

(06) Desse modo, o livro traz grandes contribuições para a formação de pesquisadores na área, com novas ideias e perspectivas para perenizar o debate. Por outro lado, o conteúdo do livro não se mostra de fácil aplicação no meio organizacional, seja pela forma acadêmica de redação, seja pela própria complexidade do assunto.

Nesse trecho, após mencionar as "grandes contribuições" que o livro traz, o resenhista introduz uma crítica, ao dizer que "o conteúdo do livro não se mostra de fácil aplicação no meio organizacional”, tendo em vista a complexidade do tema e a linguagem acadêmica. Essa mudança de perspectiva é sinalizada, no trecho, pela expressão conectiva "por outro lado".

Expomos essas quatro ações e a ordem típica em que são realizadas por meio da representação praxeológica apresentada na figura 1.

Figura 1 - Representação praxeológica do gênero resenha acadêmica

Apresentação $\rightarrow$ Caracterização $\rightarrow$ Avaliação de partes $\rightarrow$ Recomendação ou não

Realizada a análise do módulo referencial, o próximo passo do estudo consistiu na análise da forma de organização sequencial das resenhas.

\section{ANÁLISE DA FORMA DE ORGANIZAÇÃO SEQUENCIAL}

No modelo modular, essa forma de organização trata basicamente da segmentação do discurso em sequências. Para isso, busca, de um lado, definir uma tipologia discursiva que possa ser aplicada a todas as produções linguageiras e, de outro, extrair as sequências discursivas em que os tipos de discurso se atualizam.

A definição dos tipos e a segmentação do discurso em sequências mobilizam informações do módulo referencial, responsável por definir as categorias pré-linguageiras, e do módulo hierárquico, responsável por definir os processos textuais em que essas categorias se manifestam. Combinando informações desses dois módulos, o modelo modular estabelece uma tipologia formada por três tipos de discurso: narrativo, descritivo e deliberativo. Esses tipos constituem representações abstratas, cuja função é possibilitar a emergência das sequências discursivas (narrativas, descritivas e deliberativas) (FILLIETTAZ, 1999, ROULET; FILLIETTAZ; GROBET, 2001, CUNHA, 2013).

No modelo, o tipo narrativo é definido como "o esquema de uma intervenção textual, tendo por propriedade designar uma pluralidade de acontecimentos disjuntos do mundo comum, no qual acontece o processo da comunicação" (ROULET; FILLIETTAZ; GROBET, 2001, p. 316). Filliettaz (1999) defende que as diferentes formas de expressão da narratividade representam acontecimentos que se articulam em uma cadeia culminativa formada pelos episódios estado inicial, complicação, reação, resolução e estado final. 
O tipo descritivo se caracteriza por uma representação conceitual típica, a qual, a partir dos trabalhos de Adam (1992), se define como uma configuração recursiva de operações cognitivas, que são a ancoragem, $a$ aspectualização, a relação e a tematização.

- Ancoragem: toda descrição se refere a uma entidade referencial determinada. Por isso, ela se ancora em um "tema-título".

- Aspectualização: na descrição, apresentam-se as características do "tema-título", evocando as partes de que se compõe ou suas propriedades.

- Relação: o "tema-título" pode ser relacionado a outras entidades referenciais por comparação ou por metáfora.

- Tematização: uma parte do "tema-título" pode ser tematizada, ou seja, transformada em um novo "tema-título" de uma nova sequência descritiva.

Já o tipo deliberativo, ao contrário do narrativo e do descritivo, não se caracteriza, segundo Filliettaz (1999) e Roulet, Filliettaz e Grobet (2001), por configurações referenciais próprias, constituindo, por isso, "uma espécie de 'grau zero' de um modelo tipológico" (FILLIETTAZ, 1999, p. 292). Por essa razão, no modelo, esse tipo diz respeito ao conjunto das sequências discursivas que não apresentam propriedades nem da narração, nem da descrição.

Essa definição se deve ao fato de, para o modelo modular, ser difícil reduzir a diversidade das sequências deliberativas a um esquema referencial ou a um tipo de discurso único. Assim, para definir o tipo deliberativo, o modelo não busca contribuições da proposta de Adam (1992, 1999), não podendo esse tipo ser identificado com os protótipos da sequência argumentativa ou da explicativa elaborados por esse autor. Dessa forma, o modelo não considera possível a proposição de um tipo argumentativo.

Entretanto, contrariando esse postulado do modelo, consideramos, com base nos trabalhos de Adam, que a proposição de um tipo argumentativo é possível, tendo em vista as semelhanças verificáveis entre os segmentos que se caracterizam pela tentativa do locutor de convencer o interlocutor acerca da pertinência das informações expressas. Por isso, neste trabalho, valemo-nos de contribuições em especial de Adam (1992, 1999) para caracterizar as sequências argumentativas do gênero resenha acadêmica.

Para Adam, a sequência argumentativa típica apresenta estas macroproposições:

(1) tese anterior, parte na qual se apresenta e se delimita o tema sobre o qual se formula o ponto de vista;

(2) dados (ou premissas), parte em que se apresentam informações que serão usadas na defesa do ponto de vista;

(3) escoramento de inferências (ou desenvolvimento), parte em que ocorre a defesa do ponto de vista, com base nas premissas;

(4) conclusão, parte a que se chega por dedução lógica e que traz uma nova tese.

Nesse tipo de discurso, a finalidade é comentar e/ou avaliar ideias, opiniões, na tentativa de mudar a visão do outro sobre essas ideias e opiniões. Adam (1992, p. 118) representa o protótipo da sequência argumentativa por meio da figura 2:

Figura 2 - Protótipo da sequência argumentativa

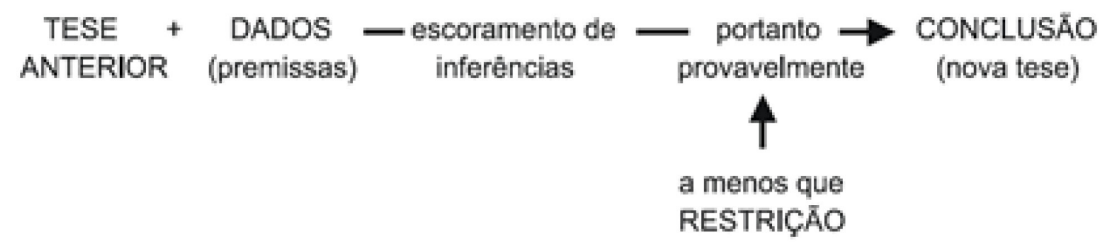

Nesta etapa da análise das resenhas, os resultados evidenciaram que elas são compostas não apenas por sequências argumentativas, mas também por sequências descritivas. Esses resultados contrariam, assim, a 
hipótese mencionada no início deste trabalho de que, por ser a resenha um gênero eminentemente persuasivo, seus exemplares poderiam ser compostos somente por sequências pertencentes ao tipo argumentativo.

Este segmento, retirado de uma das resenhas, constitui um exemplo de sequência descritiva.

(07) Em seu novo livro que acaba de ser lançado no Brasil, Omar Aktouf (professor titular da École des Hautes Etudes Commerciales, afiliada à Universidade de Montreal, Québec, Canadá) convida-nos a buscar compreender, por meio de uma perspectiva atenta e crítica, os vínculos conceituais e empíricos do pensamento econômico dominante e de suas relações com a administração.

Nesse segmento, a entidade descrita (ou tema-título) é o livro resenhado. Duas propriedades dessa entidade são apresentadas, por meio da operação de aspectualização. Primeiro, é apresentado o autor, Omar Aktouf, e suas credenciais acadêmicas ("professor titular da École des Hautes Etudes Commerciales"). Depois, é apresentado o tema do livro ("os vínculos conceituais e empíricos do pensamento econômico dominante e de suas relações com a administração”). Essa análise evidencia que, embora no trecho haja um segmento avaliativo ("por meio de uma perspectiva atenta e crítica"), esse trecho se constitui globalmente como uma sequência descritiva.

Já este trecho exemplifica uma sequência argumentativa.

(08) Como afirmado pelo próprio autor, "esta obra traz uma interpretação (certamente não exaustiva) da evolução dos conceitos, teorias e críticas em gestão estratégica de pessoas” (p. XV). É um livro que se diferencia dos demais na forma abrangente de apresentação da evolução histórica do campo, situando os leitores menos familiarizados com a área e proporcionando uma visão geral sobre a maneira como a temática surgiu e como se encontra o patamar atual de desenvolvimento. Nesse aspecto, ele se torna um livro atraente, especialmente para o público acadêmico. Desse modo, o livro traz grandes contribuições para a formação de pesquisadores na área, com novas ideias e perspectivas para perenizar o debate. Por outro lado, o conteúdo do livro não se mostra de fácil aplicação no meio organizacional, seja pela forma acadêmica de redação, seja pela própria complexidade do assunto.

Nessa sequência, a tese anterior se constitui da declaração do autor sobre o livro: "Como afirmado pelo próprio autor, 'esta obra traz uma interpretação (certamente não exaustiva) da evolução dos conceitos, teorias e críticas em gestão estratégica de pessoas". Nesse segmento, o resenhista delimita o tema sobre o qual vai formular seu ponto de vista.

Em seguida, ele apresenta os dados (ou premissas) ou as informações que serão usadas na defesa do ponto de vista: "É um livro que se diferencia dos demais na forma abrangente de apresentação da evolução histórica do campo, situando os leitores menos familiarizados com a área e proporcionando uma visão geral sobre a maneira como a temática surgiu e como se encontra o patamar atual de desenvolvimento".

Com base nesses dados, o resenhista pode, então, defender seu ponto de vista ou realizar o escoramento de inferências (ou desenvolvimento): "Nesse aspecto, ele se torna um livro atraente, especialmente para o público acadêmico".

Por fim, depois de defender seu ponto de vista sobre a obra, o resenhista conclui a sequência, trazendo uma nova tese, à qual chega por dedução lógica: "Desse modo, o livro traz grandes contribuições para a formação de pesquisadores na área, com novas ideias e perspectivas para perenizar o debate. Por outro lado, o conteúdo do livro não se mostra de fácil aplicação no meio organizacional, seja pela forma acadêmica de redação, seja pela própria complexidade do assunto”. Nessa conclusão, introduzida pela expressão conectiva "desse modo" e já estudada no item anterior, o resenhista recomenda o livro, apesar da falha que identificou.

Em algumas sequências argumentativas, a conclusão não é explicitada na superfície textual, mas pode ser inferida.

(09) A obra encerra-se com o artigo de Charles Kirschbaum sobre o nascimento da indústria de filmes no Brasil. É o único artigo em todo o livro que oferece item especial com direções para pesquisa futura. Sendo um dos objetivos da obra disseminar conhecimento, suscitar interesse e angariar a simpatia de pesquisadores, teria sido interessante ter mais espaços como este ao longo do livro, talvez em capítulo adicional, não só à guisa de encerramento e conclusão, mas oferecendo ao leitor uma proposta de agenda 
de pesquisa ou mesmo um breve elenco de possibilidades sobre temas, autores e discussões relevantes para o futuro dos estudos sobre redes sociais e sociologia econômica no Brasil.

Nessa sequência, a tese anterior se constitui deste segmento: "A obra encerra-se com o artigo de Charles Kirschbaum sobre o nascimento da indústria de filmes no Brasil. É o único artigo em todo o livro que oferece item especial com direções para pesquisa futura”. Em seguida, o resenhista apresenta as informações que vão sustentar seu ponto de vista: "Sendo um dos objetivos da obra disseminar conhecimento, suscitar interesse e angariar a simpatia de pesquisadores". Por fim, ele defende seu ponto de vista, com base nas informações dadas precedentemente: "teria sido interessante ter mais espaços como este ao longo do livro, talvez em capítulo adicional, não só à guisa de encerramento e conclusão, mas oferecendo ao leitor uma proposta de agenda de pesquisa.” Não há, portanto, uma conclusão explícita, na qual o resenhista poderia não recomendar do livro ou recomendá-lo, apesar da falha identificada.

Não foram identificadas sequências narrativas nas resenhas estudadas, o que se explica pela finalidade do gênero. Sendo essa finalidade a de convencer o leitor a adquirir ou não uma obra, a resenha precisa descrever o livro e argumentar por que ele deve ou não ser adquirido. Não é, portanto, uma expectativa associada a esse gênero a presença de sequências narrativas em sua estrutura sequencial.

\section{ANÁLISE DA FORMA DE ORGANIZAÇÃO COMPOSICIONAL}

Nessa forma de organização, o objetivo é ultrapassar a análise estrutural oferecida pela etapa anterior, realizando um estudo pormenorizado das propriedades formais e funcionais das sequências discursivas efetivamente produzidas. Assim, identificados os tipos e feita a segmentação do discurso nas sequências que o compõem, essa forma de organização busca completar a análise da heterogeneidade composicional, investigando as especificidades linguísticas e hierárquico-relacionais das sequências, bem como as funções que exercem em relação ao cotexto e ao contexto (ROULET; FILLIETTAZ; GROBET, 2001, CUNHA, 2010, 2013).

Em vista dos objetivos deste trabalho, esta etapa investigou o papel que as sequências discursivas exercem na representação praxeológica das resenhas. Essa investigação se fez a partir da acoplagem das análises desenvolvidas nas etapas anteriores sobre o módulo referencial e sobre a forma de organização sequencial.

A acoplagem das análises revelou que as sequências descritivas são os recursos semióticos empregados pelos resenhistas para realizar as duas primeiras ações de composição de uma resenha. Assim, as ações de apresentar o livro e de caracterizar o tópico de cada capítulo ou das partes do livro são realizadas preferencialmente por meio de sequências descritivas.

Já as sequências argumentativas são os recursos usados pelos resenhistas para realizar as outras duas ações da representação praxeológica: avaliar partes do livro e recomendar ou não o livro. Vale notar que, em alguns casos, uma só sequência argumentativa foi empregada para realizar essas duas ações. É o que ocorre em sequência já analisada no item anterior e reproduzida abaixo.

(10) Como afirmado pelo próprio autor, “esta obra traz uma interpretação (certamente não exaustiva) da evolução dos conceitos, teorias e críticas em gestão estratégica de pessoas” (p. XV). É um livro que se diferencia dos demais na forma abrangente de apresentação da evolução histórica do campo, situando os leitores menos familiarizados com a área e proporcionando uma visão geral sobre a maneira como a temática surgiu e como se encontra o patamar atual de desenvolvimento. Nesse aspecto, ele se torna um livro atraente, especialmente para o público acadêmico. Desse modo, o livro traz grandes contribuições para a formação de pesquisadores na área, com novas ideias e perspectivas para perenizar o debate. Por outro lado, o conteúdo do livro não se mostra de fácil aplicação no meio organizacional, seja pela forma acadêmica de redação, seja pela própria complexidade do assunto.

A ação de avaliar um aspecto específico do livro corresponde à maior parte da sequência argumentativa e é realizada pela tese anterior, pelos dados e pelo escoramento de inferências. Essa parte vai de "Como afirmado pelo próprio autor” até “especialmente para o público acadêmico”. Já a ação de recomendar o livro, apesar da falha identificada, corresponde apenas à conclusão da sequência, que vai de "Desse modo, o livro traz grandes contribuições” até o final do trecho. 
Com a figura 3, procuramos sintetizar os resultados desta etapa da análise, que consistiu em combinar a análise do módulo referencial sobre a representação praxeológica da resenha e a análise da estrutura sequencial de exemplares desse gênero.

Figura 3 - Acoplagem das análises referencial e sequencial

\begin{tabular}{|ll|l|}
\hline Análise referencial & Análise sequencial \\
\hline Apresentar o livro & $\rightarrow$ & Descrição \\
Caracterizar o livro & $\rightarrow$ & Descrição \\
Avaliar partes do livro & $\rightarrow$ & Argumentação \\
Recomendar ou não o livro & $\rightarrow$ & Argumentação \\
\hline
\end{tabular}

Essa acoplagem das análises referencial e sequencial é relevante, porque permite chamar atenção para um aspecto fundamental do gênero em estudo. Como mencionado no início deste trabalho, a resenha é um gênero bastante persuasivo, tendo em vista sua função de permitir a um especialista avaliar a contribuição que uma obra traz para uma dada área dos conhecimentos, bem como as características da composição e a capacidade do autor (MOTTA-ROTH; HENDGES, 2010).

Desse modo, ainda que as resenhas não sejam homogêneas do ponto de vista composicional, pois são formadas por sequências argumentativas e descritivas, as sequências argumentativas são as mais importantes para que o resenhista possa alcançar seus objetivos. Afinal, é por meio delas que ele avalia partes do livro e recomenda ou não sua leitura. Tanto é assim que um texto que se limite a apresentar e a caracterizar um livro, sem nenhuma marca de argumentação, dificilmente será considerado uma resenha, podendo talvez ser considerado um resumo. Nesse sentido, as sequências descritivas, na estrutura composicional do gênero resenha, estão a serviço das sequências argumentativas. A presença de sequências descritivas, mostrando a obra, constitui a base ou o ponto de partida para que o resenhista possa argumentar sobre a relevância ou não dessa obra.

Esse papel acessório que as sequências descritivas exercem na resenha se explica, então, pela própria natureza persuasiva desse gênero, que faz com que todos os elementos linguísticos e textuais estejam a serviço da argumentação.

\section{CONSIDERAÇÕES FINAIS}

Neste trabalho, procuramos verificar a pertinência da hipótese segundo a qual os exemplares do gênero resenha seriam formados exclusiva ou predominantemente por sequências argumentativas, tendo em vista a dimensão persuasiva desse gênero, especializado em convencer o leitor a adquirir ou não uma obra recentemente publicada. Assim, nosso objetivo foi o de investigar o impacto das propriedades situacionais do gênero sobre sua estrutura composicional e explicitar o papel que as sequências discursivas exercem nessa estrutura.

Para alcançar esse objetivo, o estudo de quatro resenhas publicadas em periódicos da área de Ciências Sociais Aplicadas se fez com base nos instrumentos teóricos e no método de análise do Modelo de Análise Modular do Discurso. Esse estudo se desenvolveu em três etapas. Primeiro, realizou-se a análise do módulo referencial, por meio da qual se chegou à representação praxeológica do gênero resenha. Ao compor um exemplar desse gênero, um resenhista realiza tipicamente as ações de 1) apresentar o livro, 2) caracterizar o livro, 3) avaliar partes do livro e 4) recomendar ou não o livro.

Depois, estudou-se a forma de organização sequencial das resenhas. Os resultados dessa etapa mostraram que a hipótese da exclusividade de sequências argumentativas no gênero resenha não se sustenta, uma vez que sequências descritivas também participam de sua composição. 
Por fim, na terceira etapa, as análises desenvolvidas nas duas primeiras foram combinadas para se chegar a uma compreensão de quais são as funções que essas sequências exercem no nível praxeológico do discurso. Constatou-se que as sequências descritivas são empregadas para realizar as ações de apresentar o livro e de caracterizar o tópico de cada capítulo ou das partes do livro. Já as sequências argumentativas são usadas para realizar as ações de avaliar partes do livro e de recomendar ou não o livro.

Esses resultados são importantes, porque revelam que a resenha não é um gênero homogêneo do ponto de vista composicional. Ou seja, a estrutura composicional da resenha não é formada apenas por sequências argumentativas. Além disso, os resultados mostram que, se as resenhas não são inteiramente formadas por sequências argumentativas, estas são os recursos mais importantes de que os resenhistas se valem para alcançar a finalidade principal do gênero, que é o de convencer o leitor a adquirir ou não uma obra recentemente publicada. Afinal, as ações propriamente avaliativas da representação praxeológica são realizadas por esse tipo de sequências.

\section{REFERÊNCIAS}

ADAM, J. M. Les textes: types et prototypes. Paris: Nathan, 1992.

ADAM, J. M. Linguistique textuelle: des genres de discours aux textes. Paris: Nathan, 1999.

BURGER, M. Encenações discursivas na mídia: o caso do debate-espetáculo. In: MACHADO, I. L.; MARI, H.; MELLO, R (Org.). Ensaios em análise do discurso. Belo Horizonte: Núcleo de Análise do Discurso/Faculdade de Letras/UFMG, 2002, p. 201-222.

CARVALHO, G. Gênero como ação social em Miller e Bazerman: o conceito, uma sugestão metodológica e um exemplo de aplicação. In: MEURER, J. L.; BONINI, A.; MOTTA-ROTH, D. (Orgs.). Gêneros: teorias, métodos, debates. São Paulo: Parábola Editorial, 2005, p. 130-149.

CUNHA, G. X. O sequenciamento de textos como estratégia discursiva: uma abordagem modular. 2008. 250f. Dissertação (Mestrado em Linguística) - Faculdade de Letras, Universidade Federal de Minas Gerais, Belo Horizonte, 2008.

CUNHA, G. X. A atuação de sequências do tipo narrativo em um texto jornalístico impresso. Revista do GEL, v. 7, 2010, p. 202-219.

CUNHA, G. X. A construção da narrativa em reportagens. 2013. 601f. Tese (Doutorado em Linguística) Faculdade de Letras, Universidade Federal de Minas Gerais, Belo Horizonte, 2013.

FILLIETTAZ, L. Vers une approche interactionniste de la dimension référentielle du discours. Cahiers de linguistique française, v. 18, 1996, p. 34-67.

FILLIETTAZ, L. Des enjeux actionnels dans les interactions verbales: une définition de la dimention référentielle du discours. Cahiers de linguistique française, v. 19, 1997, p. 47-82.

FILLIETTAZ, L. Une approche modulaire de l'hétérogénéité compositionnelle du discours: le cas des récits oraux. Cahiers de linguistique française, v. 21, 1999, p. 261-327.

FILLIETTAZ, L. Actions, activités et discours. 2000. 403f. Tese (Doutorado em Linguística) - Faculdade de Letras, Universidade de Genebra, Genebra, 2000.

FILLIETTAZ, L. La co-construction des requêtes. Le cas du service à la clientèle dans les grandes surfaces. In: KERBRAT-ORECCHIONI, C.; TRAVERSO, V. (Orgs.) Les interactions en site commercial: invariants et variations. Lyon: Ens Éditions, 2008, p. 77-103.

FILLIETTAZ, L.; ROULET, E. The Geneva Model of discourse analysis: an interactionist and modular approach to discourse organization. Discourse Studies, v. 4, n. 3, p. 369-392, 2002.

MACHADO, A. R. O diário de leitura: a introdução de um novo instrumento na escola. São Paulo: Martins Fontes, 1998.

MARINHO, J. H. C. O funcionamento discursivo do item "onde": uma abordagem modular. 2002. 305f. Tese (Doutorado em Linguística) - Faculdade de Letras, Universidade Federal de Minas Gerais, Belo Horizonte, 2002. 
MARINHO, J. H. C; PIRES, M. S. O.; VILLELA, A. M. N. (Org.). Análise do discurso: ensaios sobre a complexidade discursiva. Belo Horizonte: CEFET-MG, 2007.

MOTTA-ROTH; D.; HENDGES, G. R. Produção textual na universidade. São Paulo: Parábola Editorial, 2010.

ROULET, E. Etude des plans d"organisation syntaxique, hiérarchique et référentiel du dialogue: autonomie et interrelations modulaires. Cahiers de linguistique française, v. 17, p. 123- 140, 1995.

ROULET, E. Une description modulaire de l'organisation topicale d"un fragment d"entretien. Cahiers de linguistique française, v. 18, p. 11-32, 1996.

ROULET, E.; FILLIETTAZ, L.; GROBET, A. Un modèle et un instrument d'analyse de l'organisation du discours. Berne: Lang, 2001.

Recebido em 09/08/2013. Aprovado em 06/04/2014. 